\title{
Modeling of Badminton Intelligent Teaching System Based on Neural Network
}

\author{
Ping Wang \\ Institute of Physical Education, North Minzu University, Yinchuan, 750021 Ningxia, China \\ Correspondence should be addressed to Ping Wang; 2009031@nmu.edu.cn
}

Received 25 March 2021; Revised 23 April 2021; Accepted 11 May 2021; Published 20 May 2021

Academic Editor: Wenqing Wu

Copyright () 2021 Ping Wang. This is an open access article distributed under the Creative Commons Attribution License, which permits unrestricted use, distribution, and reproduction in any medium, provided the original work is properly cited.

\begin{abstract}
With the popularity of neural networks and the maturity of network technology, fully functional intelligent terminals have become indispensable devices for people's lives, research, and entertainment. However, in the badminton teaching of people's daily exercise, the old traditional teaching mode is still used, which cannot achieve good teaching effects. In order to study the best of badminton teaching, this article is based on the previous research, by introducing neural network, using literature data method, questionnaire survey method, interview method, experimental method, and other research methods to conduct research. The intelligent learning of the network is connected, experiments are designed to be applied, and then, data analysis is conducted. The research results show that with the use of smartphone mobile learning teaching methods, the experimental group students' technical movements, theoretical knowledge, learning interest, and learning enthusiasm are about $20 \%$ higher than those of the control group, and the badminton intelligent teaching system based on neural network is better than the control group's traditional teaching methods. The satisfaction of the students in the experimental group was also higher than that of the students in the control group. Based on what network, the satisfaction of badminton teaching can reach more than $90 \%$. This student recognizes and accepts the teaching methods of intelligent teaching.
\end{abstract}

\section{Introduction}

Badminton sports were introduced to China in 1920 and gradually evolved into popular sports as the times evolved. In college physical education, badminton instruction is generally faced by ordinary college students, and the foundation of badminton technology is very weak or poor. Zero foundation: first, they face more complex badminton skills; after the normal teaching process from easy to difficult, from part to the whole, students tend to easily forget and master the technical essentials inaccurately; second, they have to face relatively boring explanations; when explaining difficult techniques, students are easily distracted and have low interest in learning.

In the process of badminton teaching in colleges and universities, it is generally faced with ordinary college students. The foundation of badminton technology is very weak or zero, first of all, facing more complex badminton skills, normal education from part to whole, from easy to difficult. After the process, students tend to forget and master the technical essentials inaccurately; secondly, when faced with relatively boring and incomprehensible technical explanations, students are easily distracted and have a low interest in learning; finally, college badminton technical teaching needs. Faced with the large number of students, it is impossible for the teacher to take into account the acceptance of each student in a short time of teaching. Many colleges and universities have relatively few badminton teaching hours, and most colleges and universities only offer badminton teaching for one semester. It takes a relatively long time to teach complex and diverse badminton. Educational progress is relatively tight, and students with relatively low receptivity cannot take care of it. Therefore, it is particularly necessary to construct a badminton intelligent education system based on a neural network [1].

For the intelligent teaching of badminton, experts at home and abroad also have a lot of research. In foreign countries, the most active research on intelligent teaching is in the United States, European countries, Japan, Canada, and so on. American universities such as Stanford, MIT, Memphis, 
Carnegie Mellon, and California have developed some intelligent prototype systems. For example, the National Science Foundation of the United States has invested US\$22.50 million in the research and development of learning and intelligent systems for human learning and creation. The Tutor system developed by Memphis University over 25 years can be used by computers to give prompts and hints to students' problems. In response, Tutor can make decisions based on typing and oral responses to the question without multiple choices and give corresponding explanations for possible grammatical or semantically incorrect language [2]. However, domestic badminton teaching started relatively late. Liu [3] pointed out in the article "Discussion on the Development Trend of Badminton in Colleges and Universities" that with the improvement of the country's comprehensive strength, quality education has become the basis for talent training; it has become more and more important to promote the overall development of school physical and psychological qualities. At the same time, the physical quality of college students has been declining year by year. With the gradual popularization of badminton, college badminton teaching also appears to be particularly important. While improving the quality of teaching, teachers should improve their own technical level and innovate teaching methods. Li [4] pointed out in the article "Study on the Practice of Multilevel Cooperative Teaching Method in Badminton Teaching" that badminton is an antagonistic sport across the net, especially doubles, which requires the tacit cooperation of two people. Therefore, it should be used in the process of badminton teaching in colleges and universities. Try more new teaching methods, and do more teaching practice in cultivating students' sense of unity and cooperation and learning interest. In his article, I tried to apply the hierarchical cooperative teaching method in the process of college badminton teaching. After experimental comparative research, the cooperative consciousness of experimental class students and the interest, initiative and enthusiasm of students in learning. These studies have provided some references for the research of this article, but due to the lack of samples in previous experiments, the experimental results are difficult to reproduce and are not operable.

This article briefly summarizes and analyzes existing intelligent education systems and neural network technologies. Aiming at the problems of learner modeling and selection of teaching strategies, based on repeated discussions in the study group, it is based on relevant educational objective theories and multiple intelligent theory, project reflection theory, and error backpropagation algorithm technology, designing and describing the theoretical model structure of intelligent guided badminton system based on neural network technology, which lays the foundation for the research of badminton intelligent teaching system and the realization of intelligent goals.

\section{Intelligent Teaching Methods of Badminton}

2.1. Neural Network. A neural network is composed of a large number of artificial neurons. Humans use computer technology to simulate and realize the functional connection of bio- logical neurons [5]. The weight of the connections between each neuron is determined by a particular learning algorithm, and the structure has a particular function. Network system: each neuron of the neural network is nonlinear, interacts and affects during operation, and has the properties of a nonlinear (dynamic) system [6]. At the same time, the neural network has the characteristics of highdimensionality (composed of many neurons, multiple input-multiple output), parallelism, distribution, self-adaptation, self-organization, and self-learning capabilities [7]. A single neuron is not complex, but a neural network of many neurons can produce very complex and very rich phenomena and consequences.

In a neural network, each neuron is an independent information unit, and the entire network system performs parallel and distributed processing [8]; its operations not only follow logical rules but can also operate in accordance with the rules of different disciplines such as physics, mathematics, neurobiology, and psychology [9]. The data acquisition module, control module, and data processing module are the three major components of the neural networkbased control system [10]. The control system of the neural network is shown in Figure 1.

Neural controllers already have huge applications in the field of automation. In recent years, great results have been achieved in the application of control systems in the fields of industry, aviation, and robotics [11]. However, few people have set foot in the field of intelligent badminton teaching, which is closely related to people's lives. Intelligent badminton teaching is only a controller and does not have thinking, that is, it cannot think and decide the control scheme of the system according to the environment [12]. The selflearning and self-adaptive characteristics of the neural network provide a solution for it [13].

Generally speaking, the algorithm of neural network is as follows:

$$
G(x, y)=\exp \left(-\frac{x^{2}+y^{2}}{2 \sigma^{2}}\right)
$$

where $\sigma$ is the mean square error. It is achieved by convolution of smoothing kernels with different $\sigma$ values with the image. The resulting expression formula is as follows:

$$
L(x, y)=-\frac{1}{\pi \sigma^{4}}\left(1-\frac{x^{2}+y^{2}}{2 \sigma^{2}}\right) \exp \left(-\frac{x^{2}+y^{2}}{2 \sigma^{2}}\right) .
$$

The effect is related to the value of $\sigma$; the smaller the $\sigma$, the smaller the smoothing effect, and the more noise

$$
Q=\frac{1}{2 a^{2} r^{-1}}\left(\frac{2 b^{2}}{a^{2} r^{-1}} p-t\right)^{-1}\left[a^{2} r^{-1} t^{2}+2\left(1-b^{2}\right) t\right]
$$

In case $a \in[-1,0] \cup[0,1]$,

$$
K=\frac{a}{2 b r} t
$$




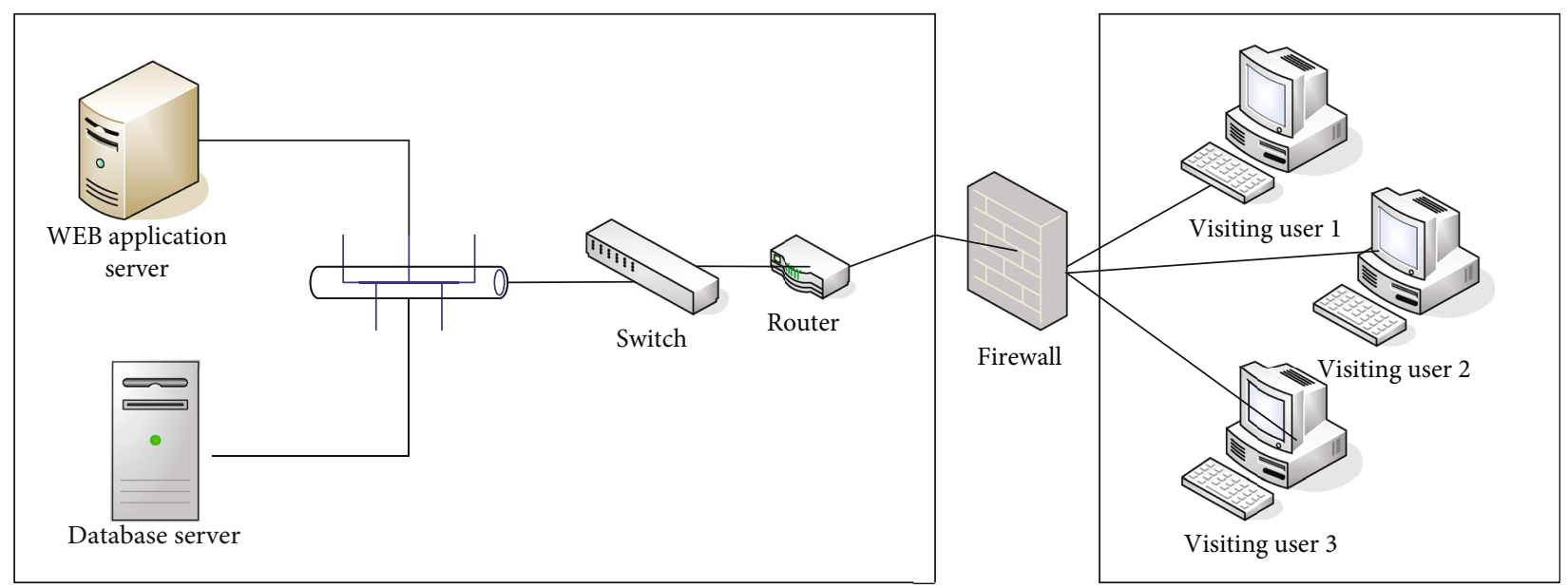

FIgURE 1: Basic framework diagram of a neural network.

$$
\lambda_{x}\left(c t_{n}-t\right)>0
$$

And so

$$
Q=\frac{1}{2 a^{2} r^{-1}}\left(\frac{2 b^{2}}{a^{2} r^{-1}} t-L\right)^{-1}\left[a^{2} r^{-1} L^{2}+2\left(1-a^{2}\right) L\right]
$$

Mathematical morphology method is to use set algebra theory to analyze and process based on geometric characteristics. Mathematical morphology methods mainly use corrosion and expansion operations to extract morphological boundaries [14]. You can get more accurate boundaries by combining the contraction effect of a calculation and the extension effect of an extension calculation with a specific logical operation. According to the idea of the maximum between-class variance method to determine the fitness function, the formula is as follows:

$$
f(t)=\sigma(t)^{2}=w_{1}(t) * w_{2}(t) *\left(u_{1}(t)\right)-u_{1}(t)^{2} .
$$

Among them, $t$ is the threshold, $f(x)$ is the fitness function, $w_{1}(t)$ is the number of nodes less than the threshold, and $w_{2}(t)$ is the number of nodes greater than the threshold [15]. Generate a random number in the interval, and select the individual corresponding to the area where the random number belongs. It can be seen that the greater the fitness of an individual, the higher the probability of being selected. The probability of an individual being selected is

$$
P_{i}=\frac{f_{i}}{\sum_{i=1}^{n} f_{i}}
$$

In this badminton intelligent teaching system, the system extracts user data from a database as input to train a neural network. That is, it uses the self-learning and self-adaptive properties of neural networks to learn the user's lifestyle. Then, according to the real-time training data, a control scheme close to the user's life habits is obtained [16]. Therefore, the intelligent badminton teaching system after the introduction of neural network can formulate badminton teaching strategies for the user's living habits according to the user's habits. Give the teaching system a "brain," and finally free users from the cumbersome traditional teaching [17]. Since this system is to learn the user's living habits in real time and then to formulate a control plan, the system can quickly adjust to this situation when the user changes or the user's habits change. The above advantages fully reflect the improvement of the intelligence of the badminton intelligent teaching system after the introduction of the neural network [18].

2.2. Smart Teaching. With the continuous promotion of intelligent learning, people's intelligent learning exchanges continue to deepen, and a large amount of semistructured data has also been accumulated in various learning platforms [19]. There are various types of data, and people organize and sort out the hidden value behind it. Educational data mining refers to mining the unique data of the education system so that the chaotic educational data becomes useful information, which can better understand students, make educational decisions for us, and optimize our badminton teaching [20].

Intelligent teaching generally refers to a digital learning support system that adaptively organizes knowledge resources, implements teaching strategies, provides teaching process services, and conducts teaching evaluation with the help of artificial intelligence and computer technology in a distributed network environment [21]. The ultimate importance of research is to give intelligence to computer systems. Computer systems replace human education to some extent to achieve the best education, reduce the workload of human teachers, improve the quality of education, enhance human understanding of the process of self-awareness, and relate. Promote the development of subjects.

Teaching not only has important value for the development of individual students but also has irreplaceable value for the development of society [22]. This is because the continuation and development of society mainly refer to the continuation and development of politics, economy, culture, and technology. The cultivation of people who develop social politics, economy, culture, and technology must be achieved 
through education, more precisely through school education. Teaching is the basic form of school education [23]. With its basic educational form, schools promote students to receive a planned, purposeful, and systematic education. Through teaching activities, students can acquire the necessary knowledge, skills, emotional attitudes and values, etc., and can promote the progress of social politics, economy, culture, and technology, thereby promoting social development. This kind of value that takes social development as the main body and serves the real life of society and the future development of society is the social value of teaching, which is based on the individual value of teaching [24].

Smart education has changed the way students acquire knowledge and has an intangible impact on traditional teaching models. Online teaching is the trend of future teaching development. Each teacher has their own advantages and disadvantages [25]. For example, some teachers are experienced but lack energy physically or due to other reasons. Some teachers are energetic but lack experience; some teachers are quick-thinking but jumping. They are more sexual; some teachers are careful and patient but not flexible enough. Online teaching is not only helpful for students to find their own learning level but also for teachers to find their own teaching level, so as to better utilize their own advantages.

University courses are independent subjects, related courses require scientific placement and research, and much energy can be spent on research to place the corresponding courses in a scientific and rational way. In order to teach courses in colleges and universities, science and correct guiding ideology are indispensable. From a long-term perspective, the arrangement of courses in colleges and universities must adhere to the concept of being "reasonable and practical" and integrate sports teaching in the context of the new era. Relevant trends of thought promote the development of students' sports awareness, so as to achieve the realization of students' self-worth, and make badminton teaching an indispensable part in the true sense.

Intelligent teaching is generally carried out in groups, and only reasonable grouping can ensure the efficiency of learning. Through analysis, we can conclude that the learning effect of students in different groups will be different. First of all, the original group leader recruitment and the free grouping of students have changed to free grouping under the guidance of teachers. Completely free grouping. Students who are more familiar in a class will get together in a group. Because each student is too familiar with each other in the group, when studying, you cannot concentrate on learning, and there are too many small chat topics. Teachers can group students reasonably on the basis of students' willingness so that everyone can have a good learning atmosphere and learn more effectively. Secondly, teachers should understand the students' personality, preferences, learning ability, and learning foundation through pretests before grouping, and grouping different students can achieve the effect of learning from each other's strengths and weaknesses. Finally, teachers should select students with organizational skills and high levels of activity as the group leader, because the activity and sense of responsibility of the group leader play a vital role in the learning of the students in the group.

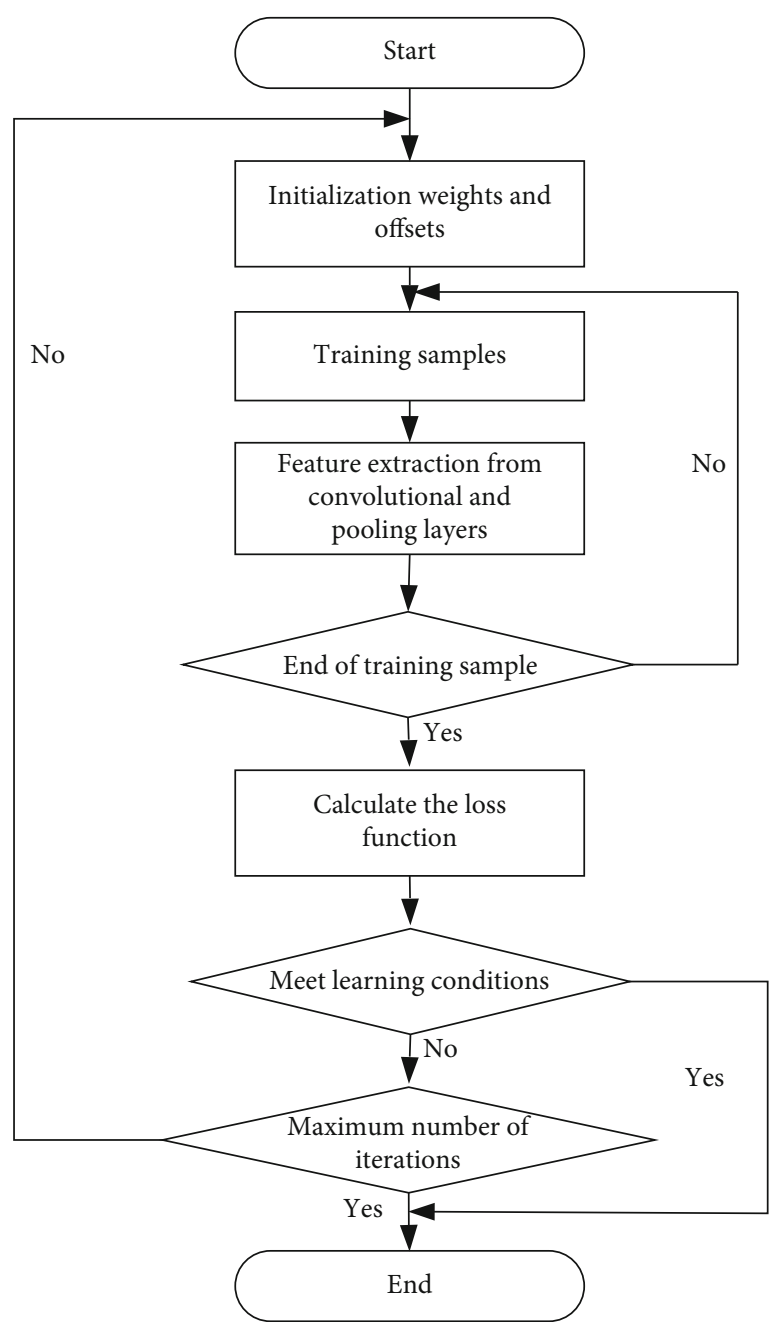

FIGURE 2: Intelligent teaching process.

2.3. Badminton Teaching. Badminton is a kind of mass sports event. Basically everyone can play, but the movements are not very standardized. Due to the lack of class hours in college badminton teaching, usually after the basic skills of badminton are taught, systematic learning and training will not be carried out. The direct badminton sparring practice did not correct some of the students' irregular movements, nor did they have time to guide and systematically complete the movement learning. Without being able to connect the courses, students find learning in class boring and boring. After completing the instruction, the teacher must prepare for the test and exam to complete the instruction progress, and the student will not practice again after the exam. In the process of badminton teaching in colleges and universities, due to the limitation of class time and insufficient time, most students are required to be taught in technology while ignoring the explanation of badminton theory.

Badminton teaching is also a sports subject with both technical and theoretical aspects, but in college badminton teaching, technical teaching still occupies the dominant position. In the process of technical teaching, it is first necessary to have venues and equipment [26]. Although currently compared to football, basketball, and volleyball courts, the football, blue, 
TABLE 1: Student level statistics.

\begin{tabular}{|c|c|c|c|c|c|c|c|}
\hline & Forehand & High forehand & Forehand lob & Forehand & Forehand rubbing & Backhand rubbing & $P$ \\
\hline Class 1 & 2.11 & 2.44 & 1.81 & 1.92 & 2.28 & 2.45 & $0.046<0.05$ \\
\hline Class 2 & 2.18 & 2.09 & 2.44 & 1.89 & 1.96 & 1.99 & $0.014<0.05$ \\
\hline Class 3 & 2.21 & 2 & 2.15 & 2.48 & 1.96 & 2.44 & $0.012<0.05$ \\
\hline Class 4 & 2.29 & 2.05 & 2.19 & 2.21 & 2.01 & 2.11 & $0.023<0.05$ \\
\hline
\end{tabular}

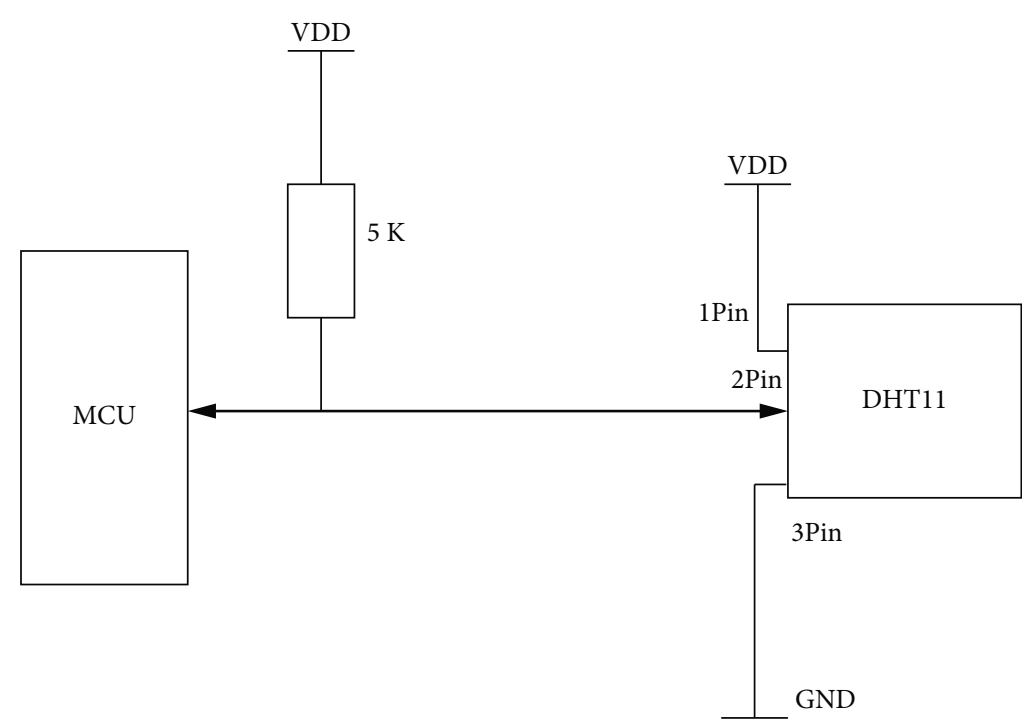

FIgURE 3: Typical application circuit.

and volleyball stadiums of many colleges and universities still occupy most of the college's sports grounds, although for badminton, the requirements for venues and other hardware facilities are relatively low. The area of badminton sports venues is generally far less than that of the three major sports venues. Therefore, many universities have to control the number of participants in badminton activities without reducing the number of classes. Badminton courts and badminton equipment are also two major obstacles.

For badminton, the purpose of students' learning is more practical, direct, and purposeful. The knowledge goal is to learn the basic knowledge of badminton, as well as badminton technology, tactics, and basic refereeing knowledge through a stage of learning. The goal of the skill is to be able to master basic badminton techniques and tactics, badminton training methods, and physical training with badminton training in class. Emotional attitude is to combine the characteristics of badminton sports [27], cultivate good physical exercise habits, and cultivate lifelong sports ideas for college students. Cultivate students to actively participate in physical exercises, and cultivate the students' hard-working spirit and the tenacious quality of persevering in hard work. The teaching process is shown in Figure 2.

\section{Experiments on Badminton Intelligent Teaching Methods}

3.1. Subjects. This paper conducts group experiments on the badminton teaching of a middle school student in this city.
One group uses traditional badminton teaching, and the other uses intelligent robot teaching based on neural network. Make full use of the research results in the field of college badminton education and teaching, construct a system for the optimization of college badminton teaching, and put forward feasibility and scientific opinions on the badminton teaching reform, so as to help colleges and universities build a badminton teaching system that is more suitable for students.

\subsection{Construction of Teaching System}

3.2.1. Neural Network Construction. We have built a machine that can perform intelligent teaching through neural network, which can teach according to the personal characteristics of students, and its operation mode is as follows.

For each input $X(k)$, calculate the output $Y(k)$ of each layer

$$
\begin{gathered}
Y(k)=\left[y_{1}(k), y_{n}(k)\right], \\
y_{j}^{i}(k)=\phi\left(s_{j}^{k}(k)\right)=\frac{1}{1+e^{-s_{j}^{i}(k)}}, \\
s_{j}^{i}(k)=\sum_{i=0}^{N_{i-1}} W_{j i}^{i} y_{i}^{i-1}(k)=\left(W_{j}^{i}\right)^{t} Y^{i 1}(k),
\end{gathered}
$$

$$
\begin{gathered}
\left(W_{J}^{I}\right)^{T}=\left[w_{j 0}^{i}, w_{j 1}^{i}, \cdots, w_{j N-1}^{i}\right], \quad w_{j 0}^{i}=-\theta_{j}^{1}, \\
\left(Y^{l}(k)\right)^{t}=\left[1 \cdot y_{1}^{i}(k), \cdots, y_{N 1}^{i}(k)\right] .
\end{gathered}
$$



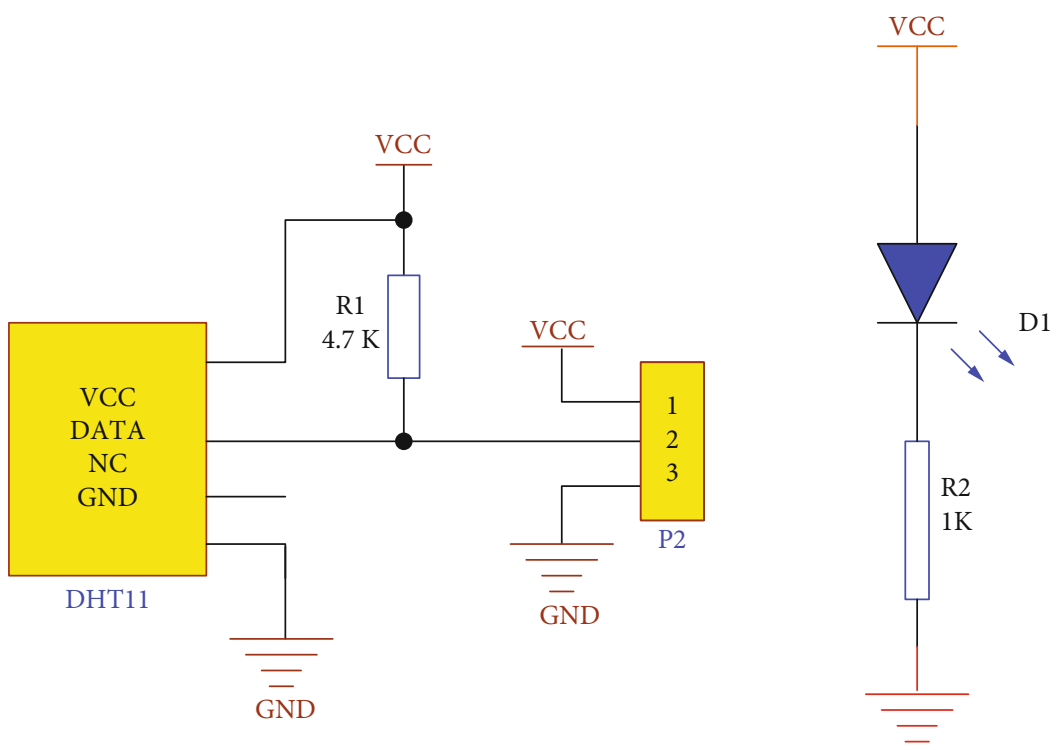

FIGURE 4: DHT11 schematic diagram.

From this, we can get the general situation, that is, for any $i$ -th layer, there is

$$
\Delta w_{j i}^{l}(k)=\delta_{j}^{l}(k) y_{i}^{l-1}(k)
$$

Among them,

$\delta_{j}^{l}(k)=\left\{\begin{array}{l}y_{j}^{l}(k)\left(1-y_{j}^{l}(k)\right)\left(d_{j}(k)-y_{j}^{l}(k)\right), \text { to the output layer, } y_{j}^{l}(k)=y_{j}(k), \\ y_{j}^{l}(k)\left(1-y_{j}^{l}(k)\right) \sum_{q} \delta_{q}^{l+1}(k) w_{q j}^{l+1}(k), \quad l \leq L-1, \text { to layer } 1, y_{j}^{0}(k)=x_{i}(k) .\end{array}\right.$

3.2.2. Student Parameter Statistics. We make statistics on the badminton level of 4 classes in a middle school so that we can compare the level changes after different teaching, as shown in Table 1.

3.3. Determine the Evaluation Weight. The index weight is a numerical index indicating the importance and function of the index. In the indicator system of the evaluation plan, the weight of each indicator is different. Even if the indicator level is the same, the weight is different. Index weight is also called weight and is usually represented by $a$. It is a number greater than zero but less than 1, and the sum of the weights of all first-level indicators must be equal to 1 , that is, satisfy the conditions $0<a<1$ and $\sum a-1$.

3.4. Comprehensive Evaluation Model. At present, there are two main evaluation models: one is the main factor highlight model, and the other is the weighted average model. If the weight of a single factor is significant and the evaluator has a predominant factor, you can choose a major key factor model. If the weight of the evaluation factors is relatively average, you can choose the weighted average model. These two models have their own characteristics. In the specific implementation process, the two methods can be imple-

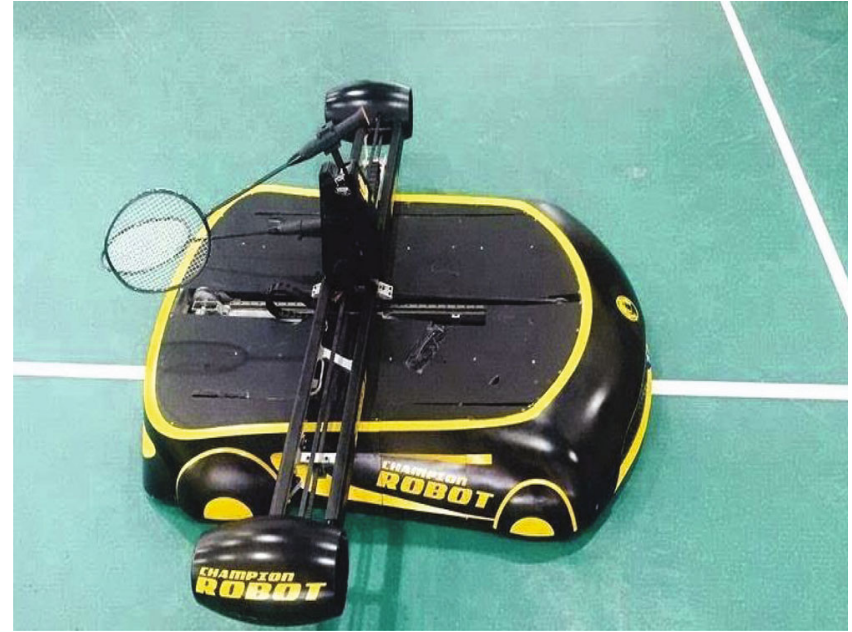

FIgURE 5: Intelligent badminton teaching machine model (from http://image.baidu.com/).

mented separately. Finally, compare the results of the two models.

\section{Badminton Intelligent Teaching Methods}

4.1. Intelligent Machine Model. In order to complete intelligent badminton teaching, our system decision-making model based on the production rules of "cause and effect" has indeed improved the level of intelligence of the system in the early application, but there are also difficulties that cannot be overcome in practice. First, teaching strategies are difficult to obtain and express. Second, the expression format of production rules is fixed, and it is difficult to maintain an educational strategy model. For this reason, we have designed an intelligent model that is more suitable for teaching. The design concept is shown in Figures 3 and 4. 
TABLE 2: Basic situation of students.

\begin{tabular}{|c|c|c|c|c|}
\hline Physical fitness & Group & Mean & $T$ & $P$ \\
\hline \multirow{2}{*}{ Height } & Test group & $176.33 \pm 7.102$ & \multirow{2}{*}{1.6003} & \multirow{2}{*}{$0.184>0.05$} \\
\hline & Control group & $174.33 \pm 6.783$ & & \\
\hline \multirow{2}{*}{ Body weight } & Test group & $65.6667 \pm 7.652$ & \multirow{2}{*}{1.4005} & \multirow{2}{*}{$0.622>0.05$} \\
\hline & Control group & $64.6667 \pm 8.015$ & & \\
\hline \multirow{2}{*}{ Badminton } & Test group & $5.266 \pm 0.125$ & \multirow{2}{*}{0.5645} & \multirow{2}{*}{$0.602>0.05$} \\
\hline & Control group & $5.233 \pm 0.359$ & & \\
\hline \multirow{2}{*}{ Standing long jump } & Test group & $2.37 \pm 0.382$ & \multirow{2}{*}{0.2031} & \multirow{2}{*}{$0.848>005$} \\
\hline & Control group & $2.34 \pm 0.295$ & & \\
\hline
\end{tabular}

Table 3: Technical level of students.

\begin{tabular}{|c|c|c|c|c|}
\hline & Experimental class & Control class & $T$ & $P$ \\
\hline Forehand & 81.6 & 80.0 & 1.789 & 0.077 \\
\hline Forehand backcourt & 77.4 & 75.8 & 1.444 & 0.153 \\
\hline Forehand to pick the backcourt high ball & 80.0 & 79.2 & 0.99 & 0.325 \\
\hline
\end{tabular}

As shown in the figure, based on the neural network model, this paper redesigns the system structure on the basis of retaining the traditional machine functions, enhances and enriches the self-organization, self-learning, and selfadaptive functions of the system decision-making model, and comprehensively improves the guidance of the system the ability to organize, make decisions, and plan for the environment and process. The final intelligent badminton teaching machine is shown in Figure 5.

Through this intelligent machine [28], we have established a direct connection between the data management model and the student model, making the entire teaching process a multivariable control state of a single-input multiple-output system and a multiple-input multipleoutput system. Teaching strategy resources include a wealth of experience-level teaching strategy resources, all of which can be continuously filled, organized, scheduled, and realtime data processed. With the network-style parallelism, intersection, and storage under the variable structure of the three major data modules of teachers, students, and data management, the teaching strategy of system decisionmaking will no longer be "solidified" and must be dynamic, diverse, and selectable.

4.2. Basic Situation of Students. Before the implementation of the teaching, we conducted a basic situation test on the two groups of students in the experimental group and the control group. The test content included physical fitness, degree of preference for badminton, learning interest, and learning enthusiasm. The data source is in the form of experimental method and questionnaire survey as shown in Table 2.

After an independent sample $t$-test $(P>0.05)$, data were measured by the physical shape and badminton-specific quality of the experimental and control classes $(P>0.05)$ and the physical shape and badminton in the experimental and control groups. You can see that there is no specific qual-
TABLE 4: Students' interest in badminton.

\begin{tabular}{lcccc}
\hline & $\begin{array}{c}\text { Very } \\
\text { interested }\end{array}$ & Interested & General & $\begin{array}{c}\text { Not } \\
\text { interested }\end{array}$ \\
\hline $\begin{array}{l}\text { Experimental } \\
\text { class 1 }\end{array}$ & 7 & 18 & 9 & 6 \\
$\begin{array}{l}\text { Experimental } \\
\text { class 2 }\end{array}$ & 9 & 12 & 11 & 5 \\
Control class 1 & 6 & 15 & 8 & 7 \\
Control class 2 & 7 & 16 & 12 & 6 \\
\hline
\end{tabular}

ity before the experiment. We have made relevant statistics on the existing badminton skills of the students in the experimental class and the control class, as shown in Table 3.

As shown in the table, the data were obtained after the test, using the analysis of variance to get the experimental class and the control class in the badminton technique of the forehand backcourt high ball, forehand hit the backcourt high ball, and forehand to pick the backcourt high ball. The $P$ values are all greater than 0.05 , which shows that there is no significant difference in the badminton skill level between the experimental class and the control class. We make statistics on the badminton interests of the two groups of people, as shown in Table 4.

From the recovery of the questionnaires sent to the students and analysis according to the display of the statistical graph, 46 students in the experimental class are interested in badminton, accounting for $59.7 \%$ of the total number. The students in the control class are interested in badminton. The number is 42 , accounting for $56 \%$ of the total; 11 people in the experimental class are not interested in badminton, accounting for $14.3 \%$ of the total number of people, and 13 people in the control class are not interested in badminton, accounting for $17.3 \%$ of the total number of people. In 


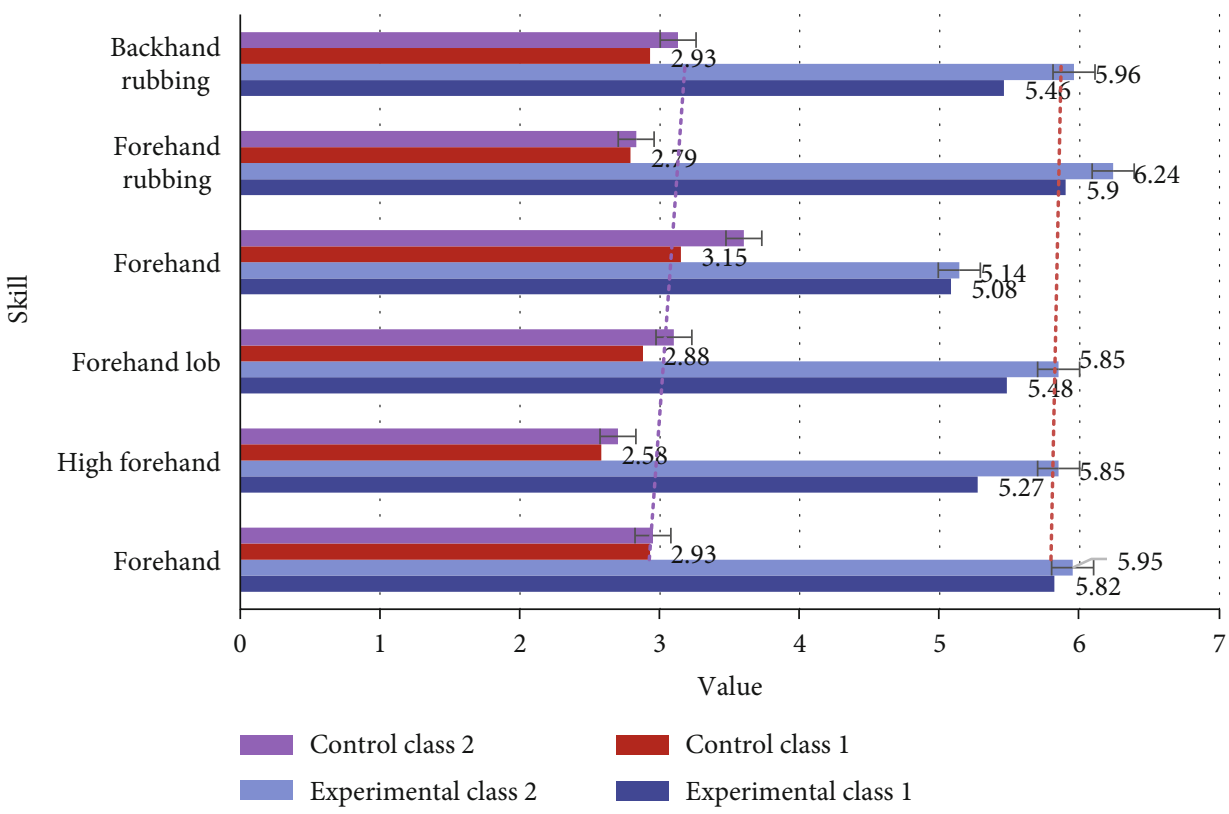

FIGURE 6: The difference between students' skills after training.

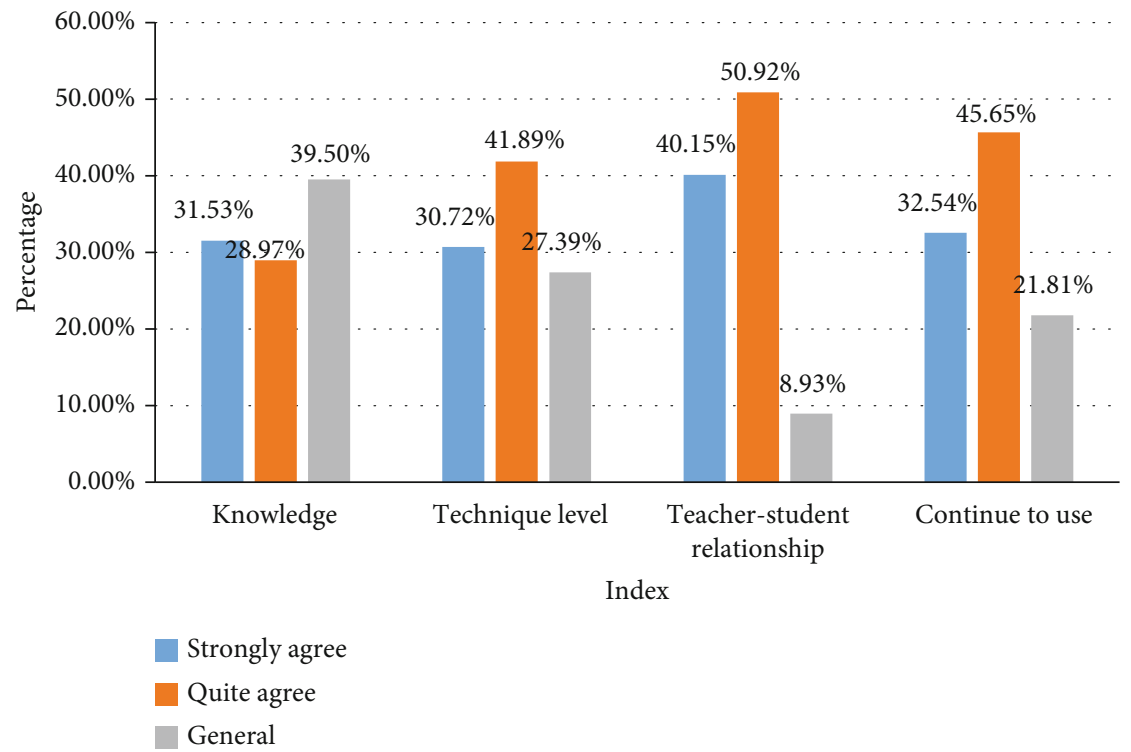

Figure 7: Student evaluation effect.

general, the percentages of the number of people interested and not interested in badminton in the experimental class and the control class are not much different. From the results of data analysis, before the teaching experiment, the students in the experimental class and the control class are interested in badminton. There is no obvious difference in the degree.

4.3. Changes before and after Training. After three weeks of training in different teaching methods, we have made statistics on the changes in the badminton level of the students in the class. The changes in badminton level are shown in Figure 6.

From the figure, we can see that after training with different teaching methods, there is a big difference in the badmin- ton level of the students. After the students in the experimental class are taught, their badminton skills have increased significantly. However, the score increase and knowledge reproduction badminton technique test results of the control class students in the second test are not very important. This result proves that there is a certain difference between the intelligent badminton teaching method under the neural network and the traditional teaching method. The intelligent teaching method has a greater advantage in consolidating and allowing students to firmly grasp the knowledge. After the teaching, we made a survey on the students' understanding of badminton, as shown in Figure 7. 
From the figure, we can see that $31.53 \%$ and $28.97 \%$ of the students who understand badminton knowledge very much agree and quite agree, and $39.5 \%$ of the average students think it is important to improve the level of badminton skills and change the relationship between teachers and students. And in the question survey that needs to continue to be used in teaching, the total proportions expressing strong agreement and relatively agree are $72.61 \%, 91.07 \%$, and $78.19 \%$, respectively; the number of disapproval is 0 . It can be seen from this that most students believe that the intelligent teaching model has advantages in improving interpersonal relationships and improving abilities. In terms of continued use of satisfaction, this teaching method can be considered acceptable and recognized.

\section{Conclusion}

By using an intelligent education system based on a neural network, students' technical movements, theoretical knowledge, interest in learning, and learning motivation are higher than those in conventional education, and student satisfaction is also higher than that in conventional teaching. It will be higher than the law. Students are more concerned about intelligent teaching. The way of learning and teaching is recognized. Smartphone mobile teaching makes the relationship between teachers and students more harmonious and intimate and improves students' enthusiasm and initiative to participate in badminton learning, and their academic performance is improved. The effect is better than traditional teaching methods. It can be passed to students positively and promote students' development of technology and knowledge capabilities. This article also has certain shortcomings. Due to my limited time and ability, the sample size of the experimental subjects is small, the implementation content of the intelligent badminton teaching method design using neural network in this article is still imperfect, and the scope of the experiment should be expanded, with further scientific and comprehensive research to increase its effectiveness. In the future, it can be studied whether it can be applied to the teaching of other subjects and whether it is more practical for girls.

\section{Data Availability}

The data underlying the results presented in the study are available within the manuscript.

\section{Conflicts of Interest}

The author declares no conflict of interest regarding the publication of the research article.

\section{Acknowledgments}

This work was supported by high-level talent funding project of North Minzu University in 2019, project number 2019BGGY04, and online open course construction project of North Minzu University in 2019, project name: theory and practice of badminton teaching, project number bmdzxk201908.

\section{References}

[1] D. Shen, "An experimental research on layered teaching in badminton optional course teaching," Sports Boutique (Academic Edition), vol. 35, no. 8, pp. 56-57, 2016.

[2] M. Ali, L. T. Jung, A.-H. Abdel-Aty, M. Y. Abubakar, M. Elhoseny, and I. Ali, "Semantic-k-NN algorithm: an enhanced version of traditional k-NN algorithm," Expert Systems with Applications, vol. 151, article 113374, 2020.

[3] M. Segler, M. Preuss, and M. P. Waller, "Planning chemical syntheses with deep neural networks and symbolic AI," Nature, vol. 555, no. 7698, pp. 604-610, 2018.

[4] D. Holden, T. Komura, and J. Saito, "Phase-functioned neural networks for character control," ACM Transactions on Graphics, vol. 36, no. 4, pp. 1-13, 2017.

[5] Y. Ganin, E. Ustinova, H. Ajakan et al., "Domain-adversarial training of neural networks," Journal of Machine Learning Research, vol. 17, no. 1, 2017.

[6] H. Lu, R. Setiono, and H. Liu, "Effective data mining using neural networks," IEEE Transactions on Knowledge and Data Engineering, vol. 8, no. 6, pp. 957-961, 2016.

[7] Y. Han, J. Kim, and K. Lee, "Deep convolutional neural networks for predominant instrument recognition in polyphonic music," IEEE/ACM Transactions on Audio Speech \& Language Processing, vol. 25, no. 1, pp. 208-221, 2017.

[8] B. Han, J. Li, S. Jinshu, M. Guo, and B. Zhao, "Secrecy capacity optimization via cooperative relaying and jamming for WANETs," IEEE Transactions on Parallel and Distributed Systems, vol. 26, no. 4, pp. 1117-1128, 2014.

[9] B.-K. Kim, J. Roh, S. -Y. Dong, and S.-Y. Lee, "Hierarchical committee of deep convolutional neural networks for robust facial expression recognition," Journal on Multimodal User Interfaces, vol. 10, no. 2, pp. 173-189, 2016.

[10] F. Dernoncourt, J. Y. Lee, O. Uzuner, and P. Szolovits, "Deidentification of patient notes with recurrent neural networks," Journal of the American Medical Informatics Association, vol. 24, no. 3, pp. 596-606, 2017.

[11] Z. Lv and L. Qiao, "Deep belief network and linear perceptron based cognitive computing for collaborative robots," Applied Soft Computing, vol. 20, article 106300, 2020.

[12] G. Suddrey, C. Lehnert, M. Eich, F. Maire, and J. Roberts, "Teaching robots generalisable hierarchical tasks through natural language instruction," IEEE Robotics and Automation Letters, vol. 2, no. 1, pp. 201-208, 2016.

[13] L. Zhou, H. Li, and K. Sun, "Teaching performance evaluation by means of a hierarchical multifactorial evaluation model based on type-2 fuzzy sets," Applied Intelligence, vol. 46, no. 1, pp. 34-44, 2016.

[14] L. Yang, "Discussion on physical education teaching reform in colleges and universities," Science \& Technology Information, vol. 16, no. 5, pp. 159-160, 2018.

[15] Z. Zhentao, "Discussion on the reform and development of physical education in primary and middle schools," Contemporary Sports Science \& Technology, vol. 6, no. 28, pp. 115116,2016

[16] Y. Liang, "The enlightenment of the "people-oriented" education view on the reform of college physical education," 
Teaching Management and Education Research, vol. 2, no. 8, pp. 30-32, 2017.

[17] Y. Wang, "Rethinking the current reform of college physical education," Sports World (Academic Edition), vol. 751, no. 1, pp. 125-126, 2016.

[18] R. Yu, "On the innovation education and the reform of middle school physical education," Xue Weekly, vol. 283, no. 7, pp. 186-189, 2016.

[19] X. Shenglong, "Research on influencing factors and development countermeasures of physical education reform in Chinese universities," Journal of Jiamusi Vocational College, vol. 159, no. 2, p. 345, 2016.

[20] J. Bin, "College physical education teaching reform from the perspective of general education," Contemporary Sports Science \& Technology, vol. 7, no. 4, pp. 7-8, 2017.

[21] L. Yang, "Employment-oriented reform of physical education in higher vocational colleges," Quality Education in West China, vol. 3, no. 14, pp. 76-78, 2017.

[22] X. Chen, "Employment-oriented reform of physical education in higher vocational colleges," Stationery \& Sports Supplies \& Technology, vol. 20, no. 381, pp. 101-102, 2017.

[23] X. Ma, "Employment-oriented reform of physical education in higher vocational colleges," New West, vol. 438, no. 11, pp. 162-163, 2018.

[24] X. Wan, "Employment-oriented reform of physical education in higher vocational colleges," Nongjia Staff, vol. 16, no. 556, pp. 205-207, 2017.

[25] H. Wang, "Research on higher vocational physical education teaching reform oriented by teaching innovation," Journal of Hubei Correspondence University, vol. 29, no. 8, pp. 129-130, 2016.

[26] Z. Lv, A. Halawani, S. Feng, H. Li, and S. U. Réhman, "Multimodal hand and foot gesture interaction for handheld devices," ACM Transactions on Multimedia Computing, Communications, and Applications (TOMM), vol. 11, no. 1s, pp. 119, 2014.

[27] M. Abdel-Basset, M. Mohamed, M. Elhoseny, L. H. Son, F. Chiclana, and A. E.-N. H. Zaied, "Cosine similarity measures of bipolar neutrosophic set for diagnosis of bipolar disorder diseases," Artificial Intelligence in Medicine, vol. 101, p. $101735,2019$.

[28] G. Dartmann, H. Song, and A. Schmeink, Big Data Analytics for Cyber-Physical Systems: Machine Learning for the Internet of Things, Elsevier, 2019. 